\title{
Políticas públicas e capital social para o desenvolvimento local da pesca e da aquicultura no Vale do Piancó, Paraíba
}

\author{
Public policy and institutional capital for local development of artisanal fishing and \\ aquaculture in the region of Vale do Piancó, Paraíba
}

\section{Politiques publiques pour le développement local et capital sociale dans la pêche artisanale et l'aquaculture dans la région Vale do Piancó, Paraíba}

\author{
Políticas públicas y capital social para el desarrollo local de la pesca de artesanía y de la \\ acuicultura en la región del Vale do Piancó, Paraíba
}

\author{
Elton José da Cunha* \\ (elton_cunha@hotmail.com) \\ Angelo Brás Fernandes Callou** \\ (abcallou@gmail.com)
}

Recebido em 30/03/2012; revisado e aprovado em 29/07/2012; aceito em 02/03/2013

\begin{abstract}
Resumo: Este trabalho realiza um mapeamento das políticas públicas para o desenvolvimento local da pesca artesanal e da aquicultura na região do Vale do Piancó, Paraíba, por meio dos projetos estabelecidos pelas organizações governamentais. Analisa-se a construção do capital social interinstitucional para implantação de projetos numa região com o potencial hídrico de 2 bilhões de metros cúbicos d'água armazenados.

Palavras-chave: Políticas públicas. Pesca. Desenvolvimento local.

Abstract: In this paper it is made a map of public policies for local development of artisanal fishing and aquaculture in the region of Piancó Valley, Paraíba, through the projects established by governmental organizations. It is analized the construction of institutional capital to implement projects in a region with the water potential of 2 billion cubic meters of stored water.

Key words: Public policy. Fishing. Local development.

Résumé : Cette étude est axée sur les politiques publiques pour le développement local de la pêche artisanale et l’aquaculture dans la région de la Vallée de Piancó, etat de Paraiba, au nordeste du Brésil. Il s`agit d`analyser la construction du capital institutionnel dans des projets établis par des organizations non gouvernamentales, dans une région dont le potentiel d`eau stoché est, environ, deux milliards de mètres cubes dèau.

Mots-clés: Politiques publiques. Pêche artisanale. Développement local.

Resumen: En este trabajo se realizará un mapa de las políticas públicas para el desarrollo local de la pesca de artesanía y de la acuicultura en la región del Vale do Piancó, Paraíba, a partir de los proyectos establecidos por organizaciones gubernamentales. Se analizará la construcción del capital social interinstitucional para la implantación de proyectos en una región con el potencial hídrico de 2 billones de metros cúbicos de agua almacenados.

Palabras clave: Políticas públicas. Pesca. Desarrollo local.
\end{abstract}

\section{Introdução}

O objetivo principal deste trabalho é mapear as políticas públicas para o desenvolvimento local da pesca artesanal e da aquicultura na região do Vale do Piancó, Paraíba, a partir de 2003, por meio dos projetos estabelecidos pelas organizações governamentais. Especificamente, pretende-se analisar, nos projetos identificados, a construção do capital social interinstitucional para o desenvolvimento local do setor pesqueiro.

A criação da Secretaria Especial de Aquicultura e Pesca da Presidência da República
(Seap/PR), em 2003, hoje Ministério da Pesca e da Aquicultura (MPA), possibilitou o ressurgimento das políticas públicas para o setor pesqueiro no Brasil, estagnadas desde o final dos anos de 1980. Isso, numa perspectiva diferenciada em relação às políticas até então levadas à pesca artesanal, pois há um chamamento à participação dos pescadores e pescadoras na construção do desenvolvimento. A partir de então, passa-se a ter um novo marco histórico para a pesca e aquicultura, de notória importância no cenário político-nacional (CALLOU et al., 2006). Esta é a principal razão de partirmos do ano de 2003 como marco deste estudo.

\footnotetext{
* Empresa de Assistência Técnica e Extensão Rural da Paraíba (Emater-PB), Cabedelo, PB, Brasil.

** Universidade Federal Rural de Pernambuco, Recife, PE, Brasil.
} 
A intenção do governo com a criação da Seap/PR é incrementar a pesca e aquicultura, por meio da formação de parcerias com estados e municípios, estimulando a participação efetiva dos pescadores e pescadoras nos processos decisórios (BRASIL, 2003). Nesse conjunto de preocupações, está implícita a perceptiva do desenvolvimento local. Oliveira (2001) afirma que o desenvolvimento local não é a solução de todos os problemas socioeconômicos advindos da adoção da estratégia de desenvolvimento, porém ele poderá contribuir para o debate sobre os problemas de exclusão social no mundo contemporâneo.

Nesses termos, a partir da criação da Seap/PR, o governo brasileiro condiciona a implementação das políticas públicas para o desenvolvimento da pesca artesanal e aquicultura às articulações interinstitucionais. Isto implica a construção de parcerias entre os diversos setores da sociedade para fortalecer o capital social. Este, aqui compreendido como as normas, valores, instituições e relacionamentos compartilhados que permitem a cooperação dentro ou entre os diferentes grupos sociais (MARTELETO; SILVA, 2004).

Sem o desenvolvimento desse capital social, portanto, dizem Callou e Tauk Santos (2003), dificilmente as políticas públicas poderão ser viabilizadas no cenário do Estado indutor. É nesse sentido que a construção do desenvolvimento local está fundamentalmente relacionada à construção de parcerias interinstitucionais. É nesse sentido, ainda, que Sawaya (2006) considera o capital social como influenciador direto na eficiência, no sucesso e na sustentabilidade das políticas públicas. Para Putnam (apud VILLA, 2006), o capital social é, também, ferramenta que estimula as ações coletivas, as quais podem ser usadas nas políticas públicas para o desenvolvimento local.

A importância do capital social na construção do desenvolvimento local nos fez refletir sobre a implantação das políticas públicas para o desenvolvimento da pesca e da aquicultura no Estado da Paraíba, mais especificamente no Vale do Piancó. A questão principal que resultou dessa reflexão é: de que forma está se construindo o capital social entre as diversas organizações presentes no Vale do Piancó para o desenvolvimento local, pautado na pesca e na aquicultura, a partir do potencial hídrico de 2 bilhões de $\mathrm{m}^{3}$ d'água armazenados nessa região?

Este trabalho diz respeito, portanto, às políticas públicas, por meio dos projetos estabelecidos pelas organizações governamentais, particularmente na área administrativa da Regional da Emater-PB Itaporanga. Essa área fica localizada no alto sertão da Paraíba, região que apresenta potencial hídrico para o desenvolvimento de atividades de pesca e aquicultura.

A regional de Itaporanga, Vale do Piancó, é uma das 15 regiões administrativas em que está dividido o Estado da Paraíba para fins de ação da Emater-PB. A sede fica no município de Itaporanga, de onde são gerenciados escritórios locais em 19 municípios, todos inseridos no alto sertão do Estado, na região conhecida como Vale do Piancó. Essa regional atende parte dos municípios que compõem a Bacia Hidrográfica do Rio Piancó (ADESE, [2008?]).

O sertão paraibano está geograficamente localizado no semiárido nordestino, local que apresenta os índices sociais, econômicos e políticos mais preocupantes do país. Contudo dados preliminares da Emater-PB (Regional Itaporanga) apontam para um potencial hídrico, principalmente em barragens e açudes. Passíveis, portanto, de serem explorados de forma sustentável, contribuindo para a melhoria desses índices socioeconômicos, em especial para o desenvolvimento local.

Nesse sentido, para alcançar os objetivos propostos por esta pesquisa, foi feito, inicialmente, um levantamento das políticas públicas para o desenvolvimento da pesca e da aquicultura na Paraíba, por meio de sites da internet, catálogos, relatórios, documentos e projetos das ONGs, empresas públicas e particulares. Posteriormente, a partir de um roteiro semiestruturado, foram realizadas entrevistas com gestores, representantes de pescadores e técnicos ligados a projetos de pesca e aquicultura, desenvolvidos por organizações governamentais no sertão do Vale do Piancó. As entrevistas tiveram como objetivo levantar informações empíricas que servissem à análise do capital social interinstitucional na implementação dos projetos no contexto estudado. Foram entrevistados seis gestores, oito técnicos e cinco beneficiados dos projetos identificados. 


\section{Políticas públicas para pesca e aquicultura no Vale do Piancó}

As instituições e suas políticas públicas direcionadas à pesca e aquicultura identificadas nesta pesquisa, por meio dos projetos elaborados, foram as seguintes:

a) Secretaria de Desenvolvimento da Agropecuária e da Pesca da Paraíba (Sedap)

Esta Secretaria é responsável pela execução de atividades de apoio ao Desenvolvimento Rural; realiza planejamento, avaliação e controle de seus programas e projetos.

Entre as atribuições da Sedap, destacam-se ações específicas de organização e melhoria da base produtiva, ações setoriais de fomento à produção animal e vegetal, ações de pesquisa e difusão de novas metodologias e tecnologias, ações setoriais específicas de geração de emprego, renda e inserção social no meio rural.

Para viabilizar suas ações, esta Secretaria conta com quatro instituições: Empresa de Assistência Técnica e Extensão Rural da Paraíba (Emater), Empresa Estadual de Pesquisa Agropecuária (Emepa), Empresa Paraibana de Abastecimento e Serviços Agrícolas (Empasa) e o Instituto de Terra da Paraíba (Interpa). Essas instituições prestam assistência técnica e extensão rural; realizam pesquisa básica; executam as políticas de abastecimento e coordenam as questões fundiárias do Estado.

Segundo informações do governo da Paraíba (PARAÍBA, [2009?]), na Sedap existem diversas ações gerais para o setor agropecuário e pesqueiro. Entre elas, destacam-se: distribuição de alevinos, fomento à pesca extensiva e intensiva de águas interiores, apoio à pesca marítima artesanal e apoio à pesca marítima industrial (terminal pesqueiro).

Algumas dessas ações ficam explícitas na fala do secretário executivo da Pecuária e Pesca da Paraíba, Fábio Agra de Medeiros Nápoles, quando afirma que "a Sedap tem a Empasa e a Gerência de Abastecimento e Pesca responsáveis pela distribuição de alevinos e a realização de projetos em toda a Paraíba." Ainda segundo o entrevistado, "entre 2003 e 2007, foram realizadas ações de distribuição de alevinos pela Empasa, criação do Conselho Estadual de Pesca e desenvolvimento do
Projeto Tilápia Paraíba, coordenado pela Secretaria Executiva da Pecuária." Entretanto não se identificou qualquer participação de entidades do Vale do Piancó no Conselho Estadual de Pesca.

\section{a.1) Projeto Tilápia Paraíba}

O projeto surgiu, em 2007, segundo o secretário executivo da Pecuária e Pesca da Paraíba, Fábio Agra de Medeiros Nápoles, a partir da articulação da Sedap com outras organizações, como a Superintendência de Administração do Meio Ambiente da Paraíba (Sudema) e a Agência Estadual de Saneamento e Água (Aesa). As reuniões desenvolvidas entre as coordenações dessas instituições, bem como com as associações de produtores, além de contatos estabelecidos com fornecedores de insumos, equipamentos e compradores de pescado, possibilitaram a mobilização em torno desse projeto.

O Projeto Tilápia Paraíba está dentro da proposta de Desenvolvimento Regional Sustentável do Banco do Brasil (BB). Essa proposta do banco traz elementos de formação de capital social para o desenvolvimento local, quando coloca como premissa a construção de parcerias para aproveitamento do potencial hídrico do Vale do Piancó (BRASIL, [2007?]).

O objetivo principal do Projeto Tilápia é beneficiar 204 famílias com produção mensal de 180 toneladas de peixes, produzidos em tanques-rede. O projeto será implantado em vinte dos principais mananciais do Estado, com financiamento do Banco do Brasil, por meio do Programa Nacional de Fortalecimento da Agricultura Familiar (Pronaf) (PARAÍBA, 2008a).

Para a implantação desse projeto, estava previsto o envolvimento de várias secretarias do Estado e de outras organizações governamentais, entre elas a Secretaria de Educação, a Secretaria da Saúde, a Secretaria da Ciência, Tecnologia e Meio Ambiente e a Companhia Nacional de Abastecimento (Conab). Os principais parceiros previstos foram o Serviço Brasileiro de Apoio às Micro e Pequenas Empresas (Sebrae), o Serviço Nacional de Aprendizagem Rural (Senar) e a Emater (PARAÍBA, 2008b).

Para o desenvolvimento do projeto, segundo entrevista realizada com o então 
secretário executivo da Pecuária e Pesca do Estado da Paraíba, foram selecionados os açudes de melhor capacidade hídrica, e providenciadas as análises de águas desses mananciais e a concessão das outorgas de uso desses recursos hídricos.

Segundo esse entrevistado, os beneficiários de alguns municípios já haviam recebido capacitação em associativismo e cultivo de peixes em tanques-rede, por meio do Senar. $\mathrm{O}$ último passo previsto, diz ainda o entrevistado, a elaboração das Declarações de Aptidão ao Pronaf (DAP) na Emater, visando obter o financiamento mediante essa linha de crédito, já se encontra em andamento.

Apesar desses depoimentos, há informações de que, até dezembro de 2007, não havia, ainda, se definido uma metodologia para análise de licenciamento e outorga do Projeto Tilápia (PARAÍBA, 2008b). Nesse sentido, houve atrasos na execução do projeto, como é o caso dos três previstos para o Vale do Piancó. Até o momento, nenhum deles foi ainda implantado. Na realidade, o desenvolvimento do capital social interinstitucional ficou comprometido para o desenvolvimento dessas ações, na medida em que cada órgão ligado à Sedap se limitava a cumprir sua função institucional sem a preocupação de estabelecer ações conjuntas nas comunidades onde os projetos seriam implantados. Por exemplo, a Empasa se limitou a produzir alevinos para o projeto, e a Emater se resumia à emissão das Declarações de Aptidão ao Pronaf (DAP).

Por outro lado, ao exigir a participação dos produtores em associações, pois a outorga de uso d'água e o licenciamento ambiental só poderiam ser adquiridos mediante uma organização formal, esse projeto levou à expansão de associações no Vale do Piancó apenas para cumprir uma exigência burocrática. Dessa forma, parece se repetir, no setor pesqueiro, a verticalidade do associativismo, que em nada contribui para a construção do Desenvolvimento Local.

Outro aspecto que dificulta a implantação do Projeto Tilápia Paraíba tem sido o enquadramento dos produtores, na época, no Pronaf D, necessário para viabilizar a participação dos produtores no projeto, tal como foi concebido. Na verdade, a maioria dos produtores só tinha renda suficiente para se enquadrar no Pronaf B. Insuficiente, portan- to, para adquirir o financiamento do Projeto Tilápia Paraíba. Assim, a impressão que se tem é de que o Projeto Tilápia é contrário às orientações do MDA, quando este afirma "que a Política de Ater reconhece a pluralidade, as diferenças regionais, a diversidade socioeconômica e ambiental existente no meio rural e nos diferentes territórios" (BRASIL, [2004?], p. 6).

b) Políticas de Extensão Pesqueira e Aquícola da Empresa de Assistência Técnica e Extensão Rural da Paraíba (Emater-PB)

No âmbito da Extensão Pesqueira, a Emater-PB desenvolve políticas relacionadas à assistência técnica aos criadores de peixes, construção de viveiros para piscicultura e peixamentos de açudes. Em 2006, segundo relatório de atividades da Emater, foram assistidos, no Estado da Paraíba, 812 piscicultores, construídos 140 viveiros e realizados peixamentos em 490 açudes (EMATER-PB, 2007b). Vale ressaltar que os peixamentos, na realidade, são realizados pela Empresa Paraibana de Abastecimento e Serviços (Empasa), cabendo à Emater-PB o simples cadastramento dos reservatórios. A construção de açudes está ligada diretamente à elaboração de projetos de financiamento que são remetidos aos agentes financeiros.

No que diz respeito ao Vale do Piancó, essas políticas foram planejadas dentro do relatório das programações anuais de atividades (Plurianual), para o período de 2004 a 2007, a serem desenvolvidas em praticamente todos os 19 municípios dessa região (EMATER-PB, [2003?]).

Para o desenvolvimento dessas atividades no campo da pesca, a Emater-PB planejou a promoção de parcerias com outras organizações governamentais, a exemplo da Secretaria de Desenvolvimento da Agropecuária e Pesca (Sedap) (EMATER-PB, 2007b).

Mensalmente, os escritórios locais da Emater-PB, ou unidades operativas, alimentam um banco de dados chamado de Relatório de Informações Mensais das Atividades (Rima). Estes são condensados em relatórios regionais, que são a fonte de dados para o escritório Estadual da Emater-PB avaliar, quantitativamente, a ação dos seus técnicos. Se utilizarmos esta fonte de dados, 
consolidada anualmente, perceberemos que a Emater-PB, regional Itaporanga, obteve resultados insignificantes, quando comparados com o seu planejamento para o ano de 2004 a 2007 (EMATER-PB, 2005, 2006, 2007a).

Com efeito, segundo o coordenador regional da Emater, no Vale do Piancó essas atividades foram desenvolvidas na região como um todo, inclusive realizando cadastramento de pescadores e açudes. Diz ele:

[...] entre 2003 e 2007, a Emater-PB participou da distribuição de alevinos em parceria com a Empasa, elaboração de projetos para pesca e alguns de piscicultura, cadastramento de pescadores entre 2003 ou 2004, cadastramento de açudes. (Nilson de Brito Lira, coordenador regional Emater, Itaporanga).

Deve-se ainda considerar a elaboração de projeto das linhas de projetos do Pronaf, por parte dos técnicos da Emater para os pescadores. Conforme afirma o próprio presidente da Colônia de Pescadores da cidade de Piancó:

[...] através da Emater foram feitos projetos diretamente com os pescadores, através do Pronaf B. (Lourival Agostinho Florêncio, presidente da Colônia de Pescadores, Piancó).

Entretanto, a julgar pelos depoimentos de chefes de escritórios e técnicos das unidades operativas da Emater no Vale do Piancó, inferimos que as atividades de Extensão Pesqueira não alcançam, efetivamente, toda a região, como deixam transparecer tanto o Planejamento Plurianual (relatórios de atividade da Emater-PB, Região de Itaporanga), quanto o depoimento do coordenador regional e do presidente da Colônia. Assim se referem os técnicos:

Nunca foi elaborado nenhum projeto nem dada assistência técnica, destinada mais para agricultores. (Célio Emídio Sousa, chefe do Escritório Emater Ibiara).

No escritório não desenvolve nenhuma ação, nenhum projeto. Por dificuldades técnicas do trabalho. (José Juacy Gomes Chagas, chefe do Escritório Emater Nova Olinda).

Em 2008 [este período extrapola a proposta nesta pesquisa], foram elaborados 12 projetos. Antes não ocorreu projeto do Pronaf B, do Banco do Nordeste do Brasil. (Geraldo Braga dos Santos, técnico do Escritório Emater Piancó).

É possível que as razões de a Emater se voltar mais efetivamente para as atividades agropecuárias da Paraíba, no Vale do Piancó, do que para as atividades de pesca, apesar do potencial hídrico da região para piscicultura, estejam ligadas à reduzida equipe técnica no âmbito da pesca e aquicultura.

Embora haja esforços da Emater-PB para capacitar novos técnicos, principalmente a partir de 2006, essa qualificação profissional não se voltou para o campo da Extensão Pesqueira. Foi o caso do treinamento de 100 profissionais por meio do convênio com a Secretaria da Agricultura Familiar, do Ministério do Desenvolvimento Agrário, e Caixa Econômica Federal (SAF/MDA/CAIXA) (EMATER-PB, 2007b).

Esses aspectos quantitativos e, sobretudo, relacionados à qualificação profissional dos técnicos para atuar na Extensão Pesqueira e Aquícola já foram assinalados tanto por pesquisadores (DIEGUES, 1995; SILVA; CALLOU, 2006; OSTRENSKY; BORGHETTI; SOTO, 2008), quanto pelos atores do setor pesqueiro, reunidos durante a II Conferência Nacional de Aquicultura e Pesca (BRASIL, 2006, p. 44).

Ainda no âmbito das atividades de Extensão, a Política Nacional de Assistência Técnica e Extensão Rural (Pnater) chama a atenção para a necessidade da construção do capital social interinstitucional para o desenvolvimento local. Assim se refere a Pnater:

Viabilizar serviços da Ater que promovam parcerias entre instituições federais, estaduais, municipais, organizações não governamentais e organizações de agricultores familiares e demais públicos anteriormente citados, estimulando a elaboração de planos de desenvolvimento municipal, territorial e/ou regional, assim como a formação de redes solidárias de cooperação interinstitucional. (BRASIL, [2004?], p. 8).

Esse fenômeno não é uma ação aleatória. A Extensão Rural e Pesqueira, na sua vertente contemporânea para o Desenvolvimento Local, pressupõe o estabelecimento de parcerias entre organizações governamentais e não governamentais para viabilizar os processos de "concertação" no meio rural e pesqueiro (FRANCO, 2001; CALLOU; TAUK SANTOS, 2003, 2006; CALLOU et al., 2006; CARVALHO, 2007).

Tanto é assim que, na II Conferência Nacional de Aquicultura e Pesca, uma das 
resoluções aprovadas revela essa necessidade de estabelecimento de parcerias. A Seap/ PR é apontada como uma das organizações possíveis de construção de um capital social interinstitucional na perspectiva do desenvolvimento local. Diz a resolução 331 da II Conferência: "A Seap faz parcerias com instituições de pesquisa, governamentais e não governamentais para elaboração, execução e acompanhamento de propostas e projetos que contemplem o Plano Estratégico de Desenvolvimento Sustentável da Aquicultura e Pesca" (BRASIL, 2006, p. 46).

A julgar pela reduzida quantidade de técnicos que atuam em Extensão Pesqueira no Estado da Paraíba, podemos inferir que o capital social interinstitucional, mediante o estabelecimento de parcerias, é ainda insuficiente para dinamizar os processos de Desenvolvimento Local no Vale do Piancó. É importante salientar, entretanto, que o desenvolvimento desse capital social está previsto nos planejamentos anuais da Emater-PB.

Considerando a importância assumida pelo capital social interinstitucional tanto do ponto de vista teórico, quanto das reivindicações dos atores sociais presentes na II Conferência, além das determinações da Pnater e Seap/PR, é de se perguntar onde reside a principal dificuldade para efetivar essa necessidade sentida. Estariam a Emater-PB e as organizações governamentais voltadas, ainda, para uma prática de Extensão Rural e Pesqueira modulada em processos verticais de comunicação?

c) O Programa Nacional de Fortalecimento da Agricultura Familiar (Pronaf) e o Banco do Nordeste do Brasil (BNB)

O Banco do Nordeste do Brasil (BNB) é um dos agentes financeiros responsáveis pela contratação dos financiamentos destinados aos agricultores familiares, dentro do Programa Nacional de Fortalecimento da Agricultura Familiar (Pronaf) na região Nordeste do Brasil.

Segundo Magalhães et al. (2006), esse programa foi incorporado ao Ministério do Desenvolvimento Agrário (MDA), a partir de 1999. Criado pelo Decreto Presidencial n. 1.946 de 28 de junho de 1996, tem como finalidade promover o desenvolvimento rural, propiciando aos agricultores familiares o aumento da capacidade produtiva, a geração de emprego e melhoria da renda. Segundo ainda esse autor, o Pronaf é uma resposta às pressões do movimento sindical rural desde o início dos anos 1990.

A finalidade principal desse programa é prover crédito agrícola e apoio institucional às categorias de pequenos produtores rurais, pescadores e aquicultores que vinham sendo alijados das políticas públicas ao longo da década de 1980 e encontravam sérias dificuldades de se manter na atividade. Criou-se, então, a categoria dos agricultores familiares, público-alvo desse programa.

A partir da criação da Seap/PR, em 2003, o Pronaf criou uma linha específica de financiamento para o desenvolvimento da pesca e aquicultura - o Pronaf Pesca. Atualmente, essa linha foi desdobrada em outras possibilidades de financiamento (SEAP, 2008).

Entretanto, para as atividades de pesca e aquicultura no Vale do Piancó, no período 2003-2007, identificamos nesta pesquisa que apenas um projeto de financiamento pelo Pronaf foi contratado no Município de Pedra Branca. Esse quadro modifica-se timidamente a partir de 2008, quando três projetos foram financiados para os municípios de Itaporanga e Conceição. Na história do BNB, a contar de 1900 até os dias atuais, houve a irrisória contratação de seis operações para o setor pesqueiro do Vale do Piancó (BNB, 2009).

Quando aliados esses dados às operações totais de crédito do Fundo Constitucional do Nordeste (FNE), no qual estão incluídos os projetos do Pronaf, podemos observar a irrelevância das operações nas atividades de pesca, numa região de reconhecida potencialidade hídrica. O que se pode inferir sobre esses resultados nas políticas de financiamento do Pronaf, na área de pesca e aquicultura no Vale do Piancó, segundo informações dos próprios gestores do programa na região, é que as informações sobre as possibilidades de acesso ao financiamento não chegam, ou não são devidamente explicadas, nas comunidades pesqueiras dos 19 municípios da região. 
d) A Empresa Paraibana de Abastecimento e Serviços Agrícolas (Empasa) e a Política de Peixamento de Açudes

A Empresa Paraibana de Abastecimento e Serviços Agrícolas foi constituída, em 1991, pela fusão de outras empresas anteriores (EMPASA, [2009?]). Hoje está ligada diretamente à Secretaria de Desenvolvimento Agropecuário e Pesca (Sedap).

Tem como objetivos principais: programar, executar e fiscalizar a política global de abastecimento de gêneros alimentícios, com vistas ao desenvolvimento das atividades de produção e consumo, além de operar na melhoria da infraestrutura da produção agrícola, e promover a expansão das atividades de piscicultura extensiva e intensiva em açudes públicos e privados.

Esta proposta está alinhada inclusive com o Plano de Desenvolvimento Sustentável do Setor Pesqueiro (Mais Pesca e Aquicultura), pois o próprio plano esclarece que é necessário desenvolver "Aquicultura em estabelecimentos rurais: Promoção de formas específicas de fomento à aquicultura e transferência de tecnologia de cultivos adequados para produção de peixes, camarões, entre outros" (SEAP, 2008, p. 17).

Vale ressaltar que, das empresas públicas estaduais da administração indireta, essa empresa é a única da Paraíba que tem como finalidade específica o setor pesqueiro - especialmente a piscicultura. Dos três programas, continuados e prioritários, um deles é destinado à piscicultura: o Programa Estadual de Piscicultura.

\section{d.1) Projeto de peixamento de açudes}

A Empasa dispõe de estações de piscicultura no Estado. Uma das maiores está situada em Itaporanga. Juntando-se sua capacidade com os berçários de Patos, Sousa e Riachão de Ararurana, chega-se a uma produção de 5 milhões de alevinos/ano (EMPASA, 2007). São produzidos indivíduos das seguintes espécies: Carpa, Tilápia, Tambaqui e Curimatã. E, a partir desta produção, é que se desenvolve o programa de peixamento estadual.

Por meio deste, é feito o peixamento (povoamento) dos grandes açudes públicos gerenciados por órgãos federais ou estaduais, atendendo também a produtores particulares, com a doação de alevinos para a produção de alimento, por meio da pesca artesanal.

Este processo ocorre por intermédio dos escritórios locais da empresa e prefeituras municipais que fazem diretamente a distribuição nos reservatórios (EMPASA, [2009?]). A fala abaixo traz elementos dos trâmites administrativos para a distribuição/doação dos alevinos. Diz o técnico:

Distribuição de alevinos é feita através de solicitação e parceria com associações regulares que devem fazer requisição através de ofício simples, discriminando a relação dos açudes e das pessoas a serem atendidas, além das quantidades solicitadas individualmente. (Francisco de Assis Brasilino Lemos, responsável técnico da Estação Empasa, Itaporanga).

Esse procedimento, segundo informações do próprio técnico, exige na realidade que uma associação devidamente registrada na Receita - pessoa jurídica - solicite através de ofício, discriminando a quantidade necessária e os produtores e/ou açudes a serem atendidos. Os municípios, em geral, podem fazer o pedido através de suas secretarias de Agricultura, que realizam o mesmo procedimento administrativo.

No Estado como um todo, no ano de 2005 foram produzidos e distribuídos 1.009.450 alevinos, beneficiando 26 municípios e 718 açudes e/ ou produtores rurais, gerando uma renda de 600 mil reais (EMPASA, 2006). No ano de 2006, foi alcançado o auge da produção, com 3 milhões de alevinos distribuídos, beneficiando 119 municípios e 1.854 açudes e/ ou produtores rurais (EMPASA, 2007). Voltou a decrescer no ano de 2007, pois foram produzidos e distribuídos 1.528.395 alevinos, beneficiando 49 municípios e 637 açudes e/ ou produtores rurais (EMPASA, 2008).

A empresa dispõe de relatórios complexos que discriminam suas ações em nível de Estado, bem como das suas regionais. Ao se analisar esse relatório, percebe-se que, no período de 2003 a 2007, quase todos os municípios do Vale do Piancó foram atendidos. Em especial, o município de Itaporanga foi o local que mais recebeu peixes.

Ao analisar a fala do representante do sindicato, questionamos a estatística da Empresa Paraibana de Abastecimento e Serviços 
Agrícolas (Empasa), haja vista que o Município de Itaporanga teria sido beneficiado entre 2003 e 2007 com números expressivos de alevinos, em detrimento dos outros municípios do Vale do Piancó. Não obstante, a fala a seguir diverge consideravelmente dos relatórios. Como diz o representante:

Até agora nunca houve nenhuma instituição, não tem distribuição de peixe, nem nada para a pesca, só tem um movimento de vez em quando, pra fazer uma pescaria no açude do governo. (André Moises Cirilo, fiscal do Sindicato de Trabalhadores Rurais de Itaporanga).

Deve-se analisar com cuidado esses dados, pois, talvez, para Itaporanga, as informações do Sindicato Rural sejam representativas, já que a entidade agrega cerca de 90 associações comunitárias rurais, tem um quadro de sete mil sócios, dos quais 400 são assíduos.

\section{e) Secretaria do Desenvolvimento Humano} do Estado da Paraíba (SEDH)

Esta Secretaria operacionaliza diversos programas, projetos, serviços e benefícios no combate às desigualdades sociais no Estado. Apesar de seu foco estar voltado às políticas assistencialistas, existem ações que estimulam atividades produtivas, promovendo a inserção social, visando à melhoria da qualidade de vida da população.

Tem como missão principal coordenar a Assistência Social do Estado da Paraíba e articular ações sociais de forma descentralizada, envolvendo todos os municípios do Estado.

Como dito anteriormente, considerando o baixo IDH dos municípios do Vale do Piancó, a Secretaria do Desenvolvimento Humano do Estado da Paraíba busca minimizar os problemas sociais existentes, por meio do aproveitamento do potencial hídrico da região. Em meados de 2006, surge o Projeto Arranjo Produtivo de Produção Superintensiva de Tilápia em Tanques-Rede.

\section{e.1) O Projeto Arranjo Produtivo de Produção Superintensiva de Tilápia em Tanques-Rede}

Concebido para atender especificamente os municípios de Itaporanga, Igaracy e Piancó, o Projeto Arranjo Produtivo de
Produção Superintensiva de Tilápia em Tanques-Rede é destinado ao desenvolvimento da piscicultura em comunidades rurais. Essa proposta surgiu para apoiar a organização social comunitária, promover a educação nutricional e gerar alternativa de renda no local. Para a execução do projeto, foi previsto o desenvolvimento de parcerias para a realização de capacitações nas áreas de processamento e beneficiamento do pescado (PARAÍBA, [2006?]). Não é explicitado, entretanto, de que maneira essas parcerias serão estabelecidas.

O projeto conta com um orçamento que totaliza o montante de $\mathrm{R} \$ 310.200,00$, mediante recursos do Fundo de Combate e Erradicação da Pobreza no Estado da Paraíba e por meio da Secretaria de Estado do Desenvolvimento Humano, dos quais $\mathrm{R} \$ 135.000,00$ são destinados à compra de tanques-rede e cerca de $\mathrm{R} \$ 120.000$,00 para a aquisição de ração. Apesar de as discussões sobre o projeto, bem como a sua submissão à apreciação dos órgãos financiadores, terem ocorrido entre 2006-2007, sua execução só foi iniciada no último trimestre de 2008 no município de Igaracy e, no primeiro trimestre de 2009, em Piancó, não tendo sido ainda operacionalizado na cidade de Itaporanga.

Mesmo sendo a proposta do projeto destinada às comunidades rurais, há opiniões, como a do diretor pedagógico, Joaquim Élson, do Coletivo dos Pequenos Produtores de Itaporanga e Região (Coopir) e da Organização da Sociedade Civil de Interesse Público (Oscip), afirmando que esse projeto tem na realidade servido aos interesses de grandes proprietários de terra, com reservatórios maiores, e que não representam o públicoalvo da ação.

\section{f) O Projeto de Redução da Pobreza Rural da Paraíba (Cooperar)}

Cooperar é um nome fantasia do Projeto de Redução da Pobreza Rural da Paraíba (PORTAL PROGRESSO, 2009). Os recursos desse projeto são oriundos de um convênio firmado entre o governo do Estado da Paraíba e o Banco Internacional para Reconstrução e Desenvolvimento (Bird) (RODRIGUES et al., 2003).

O Projeto de Redução da Pobreza Rural da Paraíba (PCPR/PB) está pautado na 
demanda das comunidades pobres do meio rural e municípios com até 7.500 habitantes, sendo essas demandas identificadas e priorizadas pela comunidade, por intermédio de assembleia geral, convocada e dirigida pela associação comunitária. Essas demandas são apresentadas na forma de subprojetos.

Estes são preparados e submetidos ao Conselho Municipal que, após proceder à análise e priorização, encaminha para as gerências regionais da Unidade Técnica do Projeto Cooperar para análise técnica, financeira e ambiental. Segundo Rodrigues et al. (2003), apesar de existir atualmente essa estratégia de planejamento, elaboração e execução coletiva, anteriormente era comum, nos manuais e demais materiais informativos relacionados a este projeto, encontrar a família rural no centro da estratégia de ação.

As demandas comunitárias eram traduzidas em subprojetos de investimentos, de pequena dimensão, com custo total máximo equivalente a US\$ 50 mil, sendo admitidos casos de exceções para valores superiores, desde que analisados e aprovados pelo Banco Mundial.

Após a assinatura do convênio entre o Cooperar e a Associação, o recurso para a execução é repassado à conta apresentada na celebração (PARAÍBA, 2002). Esses subprojetos podem ser direcionados para infraestrutura básica (eletrificação rural, açudes reservatórios, bombas, poços tubulares); produtivos (pequenos sistemas de irrigação, beneficiamento de cereais e frutas, mecanização agrícola, piscicultura) e sociais (saneamento básico, creches, centros comunitários e privadas higiênicas). Esse fato fica evidenciado na entrevista do coordenador regional, abaixo transcrita:

Implantação de projetos de tanques-rede para Santana dos Garrotes e Nova Olinda. Vinte e um tanques-rede para cada comunidade. Entre 2004 e 2005. (FRANCISCO LEITE MINERVINO, gerente regional do Cooperar, Itaporanga).

No financiamento dos subprojetos, o Banco Mundial banca setenta e cinco partes percentuais do custo total dos subprojetos aprovados; quinze partes percentuais serão de responsabilidade do Estado, e as dez partes percentuais restantes representam a participação das comunidades beneficiárias.
A contribuição das comunidades poderá ser feita em dinheiro ou com o aporte de mão de obra e de materiais disponíveis na comunidade (PORTAL PROGRESSO, 2009).

No Estado da Paraíba, no período de 2003 a 2008, foram financiados 1.308 projetos comunitários (PORTAL PROGRESSO, 2009). Já no Vale do Piancó, onde fica localizada a regional do Cooperar, em Itaporanga, que é responsável por atender todos os municípios da área em estudo, só foram operacionalizados, entre 2003 e 2007, dois subprojetos direcionados às entidades que atenderam duas associações de pescadores/piscicultores com 21 tanques-rede cada uma, conforme fala já transcrita do gerente regional do Projeto Cooperar.

Esses dois subprojetos de investimento para o cultivo de tilápia em tanques-rede foram desenvolvidos por volta de 2004. Ficou a cargo da Empresa Paraibana de Abastecimento e Serviços Agrícolas (Empasa) o acompanhamento técnico-produtivo; e do Serviço Brasileiro de Apoio às Micro e Pequenas Empresas (Sebrae), o acompanhamento organizacional e gerencial. Esses acompanhamentos foram destinados aos três primeiros cultivos (ciclo de seis meses / cada) para cada grupo a ser atendido no respectivo município. Depois desse período, as associações deveriam dar prosseguimento às atividades de forma autossustentável, ou seja, sem a atuação das instituições. Os objetivos desses projetos parece não terem sido alcançados, conforme informações fornecidas por técnico do Cooperar. Diz ele:

Entre 2004 e 2007 foram executados projetos de tanques-rede, funcionando precariamente. Foram orçados três cultivos. (Manoel Jaci, técnico de desenvolvimento rural do Cooperar, Itaporanga).

Embora o trabalho tenha sido pautado na construção coletiva por meio das organizações de piscicultores, os projetos de tanques-rede do Cooperar não lograram a sustentabilidade pretendida. Houve paralisações, como se refere um dos piscicultores participantes do projeto:

Com este projeto, esperava-se alcançar a autossuficiência a partir do terceiro ciclo, inclusive com a ampliação do projeto, porém aconteceu de forma diferente. O projeto foi paralisado e frustrou as expectativas 
(João Lopes Neto, pescador da Associação de Piscicultores e Pescadores de Santana dos Garrotes).

O Cooperar, embora condizente com a perspectiva de formação do capital social para o desenvolvimento local, se revelou, na prática, como mais um projeto com dificuldades de operacionalização no âmbito da pesca e na região do Vale do Piancó.

\section{g) Secretaria Especial de Aquicultura e} Pesca da Presidência da República (Seap/ PR), no Estado da Paraíba

Esta Secretaria foi criada pela Medida Provisória n. 103, de $1^{\circ}$ de janeiro de 2003, e referendada pela Lei n. 10.683, de maio de 2003 (BRASIL, 2003). A Seap/PR tinha atribuições para formular a política de fomento e desenvolvimento para a aquicultura e pesca no Brasil (OSTRENSKY; BORGHETTI; SOTO, 2008).

A criação da Seap/PR foi fruto de uma antiga demanda do setor pesqueiro (BRASIL, 2006). Ostrensky; Borghetti e Soto (2008) acrescentam que esse processo foi dentro de uma perspectiva de política de gestão e ordenamento do setor, mantendo o compromisso com a sustentabilidade ambiental.

Assim como em todos os Estados da Federação, na Paraíba há um escritório estadual da Seap/PR. Apesar de Carvalho (2007) demonstrar que existem dezenas de projetos que são operacionalizados pela Seap/PR em outros Estados, a exemplo de Pernambuco, na região em estudo, o Vale do Piancó, existe apenas o Projeto Tilápia no período 2003-2007.

\section{g.1) Projeto Tilápia (Seap/PR-PB)}

O Projeto Tilápia, segundo a Secretaria Especial de Aquicultura e Pesca da Presidência da República (2007b), representa um novo modelo de gestão e até uma outra oportunidade de trabalho para gerar renda e alimento. Nesse projeto, a Seap/PR fornece a capacitação e assistência técnica, o Banco do Brasil financia a instalação dos módulos, e o governo do Estado da Paraíba se responsabiliza pelo licenciamento das barragens (SEAP, 2007).

Essa parceria entre Seap/PR e Banco do Brasil, no âmbito do Programa de Desenvolvimento Regional Sustentável (DRS), asseme- lha-se ao Projeto Tilápia Paraíba, coordenado pela Secretaria Estadual de Desenvolvimento da Agropecuária e Pesca (Sedap), como já descrito anteriormente. São, portanto, projetos idênticos, mas operacionalizados por instituições distintas. Entretanto, do ponto de vista do capital social institucional, esses projetos dão sinais de não contribuírem efetivamente para o desenvolvimento local, na medida em que as divergências político-partidárias podem impedir o estabelecimento de novas parcerias, bem como a efetivação de outras. Essas divergências são percebidas na fala do secretário executivo da Pecuária e Pesca da Paraíba, a seguir:

Falta de entrosamento entre os membros dos órgãos do Estado ligados ao setor. Problemas políticos e de orgulho pessoal de alguns dificultaram a entrada de alguns técnicos no projeto.

Outro ponto negativo foi a falta de apoio da Seap/PR devido a problemas políticos. Não há uma só parceria concreta entre este órgão e o setor do pescado no Estado. (Fábio Agra de Medeiros Nápoles, secretário executivo da Pecuária e Pesca da Paraíba).

Seja como for, o Projeto Tilápia da Seap/PR no Estado da Paraíba vem atendendo, segundo esta instituição, a 150 famílias de pequenos produtores rurais de sete cidades da Paraíba nas técnicas de cultivo de peixe em tanques-rede. A meta da Seap/PR é ampliar o projeto para 30 reservatórios a fim de produzir 10 mil toneladas, com financiamento de dez milhões de reais (SEAP, 2007). Entretanto, dos cinco projetos apontados como em fase de execução na região do Vale do Piancó, para os municípios de Itaporanga, Piancó, Olho D'Água, Conceição e Santana de Mangueira, nenhum deles havia sido implantado até janeiro de 2009, segundo entrevistados para esta pesquisa. Apenas foram implantados na região os do Projeto Cooperar para criação de peixes em tanques-rede. Assim refere o presidente da Associação dos Pescadores do Açude de Cachoeira dos Alves, com relação ao município de Itaporanga:

Entre 2003 e 2007 só colocaram pra funcionar aqui na região o projeto de tanques-rede do Cooperar em Santana dos Garrotes e Nova Olinda e um treinamento do Senar, que não foi feito aqui, mas levaram 15 pessoas para fazer treinamento em Sumé e João Pessoa em 2006 (José Fransueldo da Silva, 
presidente da Associação dos Pescadores do Açude de Cachoeira dos Alves, Itaporanga).

Fechando o cerco aos projetos aqui descritos, pode-se dizer que, no Vale do Piancó, as organizações públicas empenhadas no desenvolvimento da pesca e da piscicultura na região não conseguiram, até o momento, atingir as metas estabelecidas. Fatores de ordem burocrática, de gestão pública, de frágil mobilização dos agricultores, pescadores e piscicultores e de questões político-partidárias sinalizam como motivo determinante desse processo.

\section{Capital social para o desenvolvimento local da pesca e da aquicultura no Vale do Piancó}

O capital social surge, segundo Marteleto e Silva (2004), de relacionamentos compartilhados de cooperação entre ou dentro de diferentes grupos sociais ou institucionais. Neste trabalho, consideramos a noção de capital social interinstitucional como a quantidade de relações mantidas por um grupo ou instituição que pode ser transformada em outras formas de capital (econômico, humano) e que se traduz em desenvolvimento, especificamente, em desenvolvimento local (BOURDIEU, 1983; MARTELETO; SILVA, 2004; ALBAGLI; MACIEL, 2004; FREY, 2003; SAWAYA, 2006; VILLA, 2006).

O capital social interinstitucional surge, portanto, das relações, de parcerias, de construção de redes, ou seja, nasce dos processos de comunicação ou de relações entre as organizações envolvidas em políticas de desenvolvimento local. Conforme Albagli e Maciel (2004), o capital social interinstitucional está embutido em estruturas sociais - relações entre as instituições que compõem uma região.

Apesar da importância conferida pelos autores e pela própria Pnater ao capital social, percebe-se que, no Vale do Piancó, parte das parcerias estabelecidas para o desenvolvimento da pesca e aquicultura funciona, na realidade, ora como exigência burocrática para a implantação dos projetos, ora como discurso contemporâneo para o estabelecimento de ações participativas.

O primeiro exemplo, nessa perspectiva, são as parcerias indicadas, a seguir, nos relatórios da Empasa, que se apresentaram como mera formalidade institucional nos projetos. Ou seja, essas parcerias não são constituídas a partir de uma problemática local, envolvendo as diferentes organizações e comunidades. Tal aspecto fortaleceria o capital social interinstitucional, considerado importante para instaurar processos de desenvolvimento local. Dizem os relatórios da Empasa:

[...] variadas são as parcerias técnicas: como a Sedap, Dnocs, Sebrae, Ibama, Emater, Senar, Projeto Cooperar, Prefeituras, Agrotécnicas e Associações Comunitárias, que numa ação integrada buscam desenvolver a piscicultura em águas interiores. (EMPASA, 2008, 2007, 2006, p. 4).

Essa mesma situação parece ocorrer em relação à Sedap e às empresas a ela subordinadas: a Empasa e a Emater. Nesse caso, a parceria é encontrada apenas nos documentos e, em alguns casos, reflete-se em ações locais, entretanto não dá sinal de que surgiu de um esforço dos atores sociais presentes no Vale do Piancó. Em última instância, deixa transparecer que cumpre apenas as determinações burocrático-institucionais de instâncias superiores, em nível estadual e federal.

A relação entre a Emater-PB e o Banco do Nordeste do Brasil (BNB) é mais um exemplo desse tipo de parceria. A Emater-PB presta assistência técnica e extensão rural e elabora os projetos do Programa Nacional de Fortalecimento da Agricultura Familiar (Pronaf).

Esses projetos precisam ser encaminhados a um órgão financiador para serem avaliados e possivelmente contratados. Na região do Vale do Piancó, o BNB era o único agente autorizado, no período aqui considerado, para a contratação de projetos. Essa relação de parceria está oficializada no Manual de Crédito Rural (BRASIL, [2004?]). A observação do coordenador da Emater na região reafirma essa parceria que não ocorre efetivamente na prática, mas está institucionalizada por meio de relatórios, programas e projetos. Diz ele:

A Emater-PB atua na distribuição de alevinos com a parceria da Empasa em todos os municípios de nossa região. Na elaboração dos projetos do Pronaf não há parceria, só é elaborar as propostas e enviar para o banco. (Nilson de Brito Lira, coordenador regional da Emater Itaporanga).

Fato é que, em alguns casos, as organizações conseguem pôr em prática ações no local, a partir das parcerias interinstitucionais 
estabelecidas. Entretanto parecem não fugir à regra geral de serem criadas por determinações exteriores a esse local. Assim se refere o entrevistado do BNB:

Emater... elaborou alguns projetos, o banco financiou, e a Emater que é parceira presta assistência... Instituto Nordeste Cidadania - Agroamigo: elaborou, o banco financia, e os assessores do Agroamigo acompanham os projetos. (Emanuel Messias Araújo da Silva Nóbrega, gerente do Pronaf BNB na região de Itaporanga).

A relação entre a Secretaria de Estado de Desenvolvimento da Agropecuária e Pesca (Sedap), a Emater-PB, a Agência Executiva de Gestão de Águas do Estado da Paraíba (Aesa) e a Superintendência de Administração do Meio Ambiente da Paraíba (Sudema) é mais um exemplo desse tipo de parceria interinstitucional. O que existe entre elas, na verdade, é uma hierarquia dentro do Estado da Paraíba, aspecto esse que não caracteriza uma efetiva construção de capital social interinstitucional, mas apenas uma relação burocrática. Assim, como no caso anterior, o gestor da Sedap afirma em entrevista:

Em parceria com a Sudema e a Aesa, foram selecionados os açudes de melhor capacidade hídrica, feitas as análises de águas desses mananciais e retirada das outorgas [...]. Projeto Tilápia Paraíba: [tem como parceiros] Sedap, Banco do Brasil, BNB, Sebrae, Senar, Emater, Sudema, Aesa, Ibama e associações de pescadores. (Fábio Agra de Medeiros Nápoles, secretário executivo da Pecuária e Pesca, Paraíba).

É necessário esclarecer, ainda, que essas relações de parceria, além de institucionalizadas nos documentos oficiais, ocorrem também nos discursos dos gestores das políticas públicas ou dos projetos. Possivelmente, o discurso serve para colocar a instituição no âmbito da gestão contemporânea do desenvolvimento local, que tem no estabelecimento de parcerias o ponto de partida para o crescimento do capital social interinstitucional.

Esse tipo de capital social é efetivamente gerado no Vale do Piancó a partir do envolvimento de, no máximo, três instituições, durante a execução de políticas públicas ou projetos na região, como pode ser observado nos relatos dos gestores entrevistados:

A elaboração do projeto era pela Empasa e assistência técnica, e o Cooperar foi o órgão financiador. (Francisco Leite Minervino, gerente regional Cooperar Itaporanga).

Sebrae - capacitação, Senar - capacitação, Empasa - elaboração do projeto técnico, mais assistência técnica. (Manoel Jaci, técnico de Desenvolvimento Rural do Cooperar em Itaporanga).

Tanques-Rede: Cooperar, Empasa, Sebrae, Senar... O Sebrae e Senar estiveram em todos os momentos...Distribuição de alevinos: parceria com as associações (regulares) através de ofício (simples). (Francisco de Assis Brasilino Lemos, responsável técnico da Estação da Empasa, Itaporanga).

Apesar de nosso objetivo aqui não ser o de quantificar o capital social interinstitucional, sabemos, por Bourdieu (1983), que quanto maior o número de redes de conexões estabelecidas, maiores serão as possibilidades de transformar esse capital social em outras formas de capital, como o econômico e o cultural. No caso dos projetos para o Vale do Piancó, as redes de conexões estabelecidas soam, ainda, como incipientes para instaurar o desenvolvimento local na região.

\section{Considerações finais}

O objetivo desta pesquisa foi mapear as políticas públicas por meio dos projetos estabelecidos pelas organizações governamentais para o desenvolvimento local da pesca artesanal e na região do Vale do Piancó, Paraíba, a partir de 2003. Nesse processo, não se perdeu de vista a construção do capital social interinstitucional para o desenvolvimento local.

Como observado, sete projetos foram elaborados por organizações governamentais para o desenvolvimento do setor pesqueiro do Vale do Piancó, direcionados, principalmente, a implantação de projetos de piscicultura em tanques-rede, financiamento do Pronaf, assistência técnica e peixamento de açudes públicos. Dos 19 municípios do Vale, a quase totalidade deles foi atendida por, pelo menos, um desses projetos.

Os projetos implementados para o desenvolvimento da pesca e da piscicultura no Vale do Piancó não atingiram os objetivos a que se propuseram na região. Todos não obtiveram sustentabilidade temporal, e hoje nenhum está em funcionamento. Vários fatores concorreram para o malogro desses projetos no Vale do Piancó. Do ponto de vista do capi- 
tal social interinstitucional, o que se observou nos projetos analisados é que essa dimensão importante dos processos de desenvolvimento local não foi construída a partir das interações locais entre as organizações públicas e os contextos populares da pesca na região. O capital social evidenciado nos projetos se limitou a determinações de ordem burocrático-institucional, deliberadas em instâncias superiores que extrapolam a dimensão local, que pouco contribui para o desencadeamento de processos de desenvolvimento local.

\section{Referências}

ADESE. Comitê de bacia hidrográfica do rio Piranhas-Açu - normas do processo eleitoral. Natal, [2008?]. 19p. Cartilha de divulgação.

ALBAGLI, Sarita; MACIEL, Maria Lucia. Informações e conhecimentos na inovação e no desenvolvimento local. Ci. Inf., Brasília, DF, v. 33, n. 3, p. 9-16. set./dez. 2004.

BOURDIEU, Pierre. The forms of capital. 1983. p. 46-52. Disponível em: <http:/ /econ.tau.ac.il/papers/publicf/ Zeltzer1.pdf>. Acesso em: 18 mar. 2009. Disponibilizado em arquivo digitalizado.

BRASIL. O desenvolvimento regional sustentável. Banco do Brasil, [2007?]. Cartilha de divulgação. 12p.

Secretaria Especial de Aquicultura e Pesca. $2^{a}$ Conferência nacional de aquicultura e pesca - aquicultura e pesca: uma política de desenvolvimento sustentável para o Brasil. Brasília, 2006. 71p. CD-ROM.

Ministério do Desenvolvimento Agrário. PRONAF: manual de crédito rural - plano de safra da agricultura familiar 2004-2005. Brasília, DF, [2004?]. 20p.

Politica nacional de assistência técnica e extensão rural (Pnater). Brasília, DF, 2004. 26p.

. Presidência da República. Secretaria Especial de Aquicultura e Pesca. Projeto político estrutural. Brasília, DF, jul. 2003.

CALLOU, Angelo Brás Fernandes; MC INTYRE, Jimmy Peixe; TAUK SANTOS, Maria Salett; BERGONSI, Sandra Suely Soares. O cooperativismo pesqueiro no Brasil e as linhas de financiamento: uma estratégia para o desenvolvimento local? In: CALLOU, Angelo Brás Fernandes; TAUK SANTOS, Maria Salett (Orgs.). Associativismo e desenvolvimento local. Recife: Bagaço, 2006. p. 111-126.

CALLOU, Angelo Brás Fernandes; TAUK SANTOS, Maria Salett. Extensão pesqueira e gestão no desenvolvimento local. In: PRORENDA Rural. Extensão pesqueira: desafios contemporâneos. Recife: Prorenda Rural-PE, 2003. p. 223-236.

Estratégias governamentais de comunicação para o associativismo e desenvolvimento local. In: CALLOU, Angelo Brás Fernandes; SANTOS, Maria Salett Tauk (Orgs.). Associativismo e desenvolvimento local. Recife: Bagaço, 2006. p. 69-86.
CARVALHO, Felipe Eduardo Araújo de. Extensão pesqueira e desenvolvimento local: a experiência da secretaria especial de aquicultura e pesca do estado de Pernambuco, 2003-2006. 2007. 78p. Dissertação (Mestrado) - Universidade Federal Rural de Pernambuco, Recife, 2007.

CARVALHO, Felipe Eduardo Araújo de; CALLOU, Angelo Brás Fernandes. Extensão pesqueira e desenvolvimento local: a experiência da secretaria especial de aquicultura e pesca no estado de Pernambuco, 2003-2006. Revista Interações - Revista Internacional de Desenvolvimento Local, Campo Grande, v. 9, n. 1, p. 65-76, jan/jun. 2007.

DIEGUES, Antonio Carlos. Povos e mares: leituras em sócio-antropologia marítima. São Paulo: Hucitec, 1995.

EMPRESA DE ASSISTÊNCIA TÉCNICA E EXTENSÃO RURAL DA PARAÍBA (EMATER-PB). Relatório de informações mensais das atividades (rima). Itaporanga, PB: EMATER-PB, 2007a. 5p.

Relatório de atividades 2006. Cabedelo, PB: EMATER-PB, 2007b. 32p.

Relatório de informações mensais das atividades (rima). Itaporanga, PB: EMATER-PB, 2006. 5p.

Relatório de informações mensais das atividades (rima). Itaporanga, PB: EMATER-PB, 2005. 5p.

Relatório das programações anuais das atividades (plurianual). Itaporanga, PB: EMATER-PB, [2003?]. 7p.

EMPRESA PARAIBANA DE ABASTECIMENTO E SERVIÇOS AGRÍCOLAS (EMPASA). Quem somos, [2009?]. Disponível em: <http:/ / www.empasa.pb.gov. br/somos.php>. Acesso em: 18 mar. 2009.

Empresa Paraibana de Abastecimento e Serviços Agrícolas. Relatório de piscicultura - ano: 2007. João pessoa, PB: EMPASA, janeiro de 2008.

Empresa Paraibana de Abastecimento e Serviços Agrícolas. Relatório de piscicultura - ano: 2006. João pessoa, PB: EMPASA, janeiro de 2007.

Empresa Paraibana de Abastecimento e Serviços Agrícolas. Relatório de piscicultura - ano: 2005. João pessoa, PB: EMPASA, janeiro de 2006.

FRANCO, Augusto de. Capital social: leituras de Tocqueville, Jacobs, Putnam, Fukuyama, Maturana, Castells e Levy. Brasília: Instituto de Política, 2001. p. 69-90.

FREY, Klaus. Desenvolvimento sustentável local na sociedade em rede: o potencial das novas tecnologias de informação e comunicação. Revista de Sociologia Política, Curitiba, n. 21, p. 165-185, nov. 2003.

MARTELETO, Regina Maria; SILVA, Antonio Braz de Oliveira e. Redes e capital social: o enfoque da informação para o desenvolvimento local. Ciência da Informação, Brasília, DF, v. 33, n. 3, p. 41-49, set./dez. 2004.

OLIVEIRA, Francisco de. Aproximações ao enigma: o que quer dizer desenvolvimento local? São Paulo: Programa Gestão Pública e Cidadania (Polis)/EAESP/FGV, 2001. 40p.

PARAÍBA. Governo do Estado da Paraíba. Secretaria de Desenvolvimento Humano da Paraíba. Nossa história, [2009?]. Disponível em: <www.setras.pb.govv.br/ nossahistoria.shtml>. 
. Governo do Estado da Paraíba. Governo implantará o projeto tilápia Paraíba em 20 municípios. 17 de janeiro de 2008a [2008?]. Disponível em: < www.paraiba.br.gov. br>. Acesso em: 20 mar. 2009.

Governo do Estado da Paraíba. Projeto "tilápia Paraíba" ampliará produção de peixes no estado. 14 de abril de 2008b [2008?]. Disponível em: <www.paraiba.br.gov. br>. Acesso em: 20 mar. 2009.

PARAÍBA. Governo do Estado da Paraíba/Secretaria de Estado do Desenvolvimento Humano. Projeto "Arranjo produtivo de produção superintensiva de tilápia em tanques-rede, [2006?]. 19p.

Governo do Estado da Paraíba. Manual da comunidade. João Pessoa, PB: Secretaria de Planejamento/ Projeto Cooperar, 2002. 25p.
SAWAYA, Ana Lydia. Políticas públicas: pontos de métodos e experiências. Estudos Avançados, v. 20, n. 56, p. 131-147, 2006.

SECRETARIA ESPECIAL DE AQUICULTURA E PESCA (SEAP). Mais pesca e aquicultura: plano de desenvolvimento sustentável (2008-2011). Brasília: SEAP, [2008?]. 24p.

. Secretaria Especial de Aquicultura e Pesca. Tilápia produzida no sertão da Paraíba começa a ser comercializada. mar./[2007?]. Disponível em: <http://200.198.202.145/ seap/pdf/til_sert_pb_minis.pdf / > . Acesso em: 20 mar. 2009

VILLA, Rafael Duarte. Política externa brasileira - capital social e discurso democrático na América do Sul. RBCS, v. 21, n. 61, jun. 2006. 